\title{
Molecular Diagnostics of Adult Gliomas in Neuropathological Practice
}

\author{
Sebastian Brandner \\ Department of Neurodegenerative Disease, UCL Queen Square Institute of Neurology and Division of Neuropathology, the \\ National Hospital for Neurology and Neurosurgery, University College London Hospitals NHS Foundation Trust, London \\ WC1N 3BG, United Kingdom \\ Correspondence: s.brandner@ucl.ac.uk; Tel.: + 442034484435
}

Received: 15 November 2020; Accepted: 25 November 2020

\begin{abstract}
This review focuses on adult gliomas, highlighting the most relevant biomarkers in the diagnosis of these tumours and the use of DNA methylation arrays to complement conventional molecular diagnostic techniques. The discovery and characterisation of diagnostic and prognostic biomarkers in brain tumours has significantly changed the neuropathological landscape over the last decade. These include mutations in the IDH1 and IDH2 genes in astrocytomas and oligodendrogliomas, histone H3 K27M mutations in midline gliomas, or BRAF mutations in a range of low-grade and high-grade glial and glioneuronal tumours. Other biomarkers of relevance are mutations in the TERT promoter, the ATRX gene, and genomic alterations such as $1 \mathrm{p} / 19 \mathrm{q}$ codeletion, EGFR amplification, and chromosome 7 gain and 10 loss. The development of DNA methylation profiling and algorithmic classification of brain tumours has further enhanced the diagnostic abilities of neuropathologists. Methylation profiling is particularly useful for the diagnostic workup of biopsies with an inconclusive molecular test results, small samples, or samples with indistinctive low-grade or high-grade histology. This technology has become indispensable for the risk stratification of ependymal tumours, medulloblastomas and meningiomas. Conclusion. This review highlights the importance of an integrated approach to brain tumour diagnostics and gives a balanced view of the relevance and choice of conventional and molecular techniques in the workup of adult gliomas in diagnostic neuropathology practice.
\end{abstract}

Key Words: DNA Methylation Profiling • Isocitrate Dehydrogenase • TERT Promoter Mutation • EGFR Amplification • 1p/19q Codeletion.

\section{Introduction}

The last 10 years have seen a fundamental paradigm shift in brain tumour diagnostics. The most significant discoveries were (i) the identification of mutations in the isocitrate dehydrogenase (IDH) genes 1 and 2 in astrocytomas and oligodendrogliomas (1), (ii) proto-oncogene B-Raf murine sarcoma viral oncogene homolog B (BRAF) mutations in a range of low-grade glial and glioneuronal tumours (2), (iii) histone H3 K27M mutations in pontine gliomas (3) and a subsequent discovery of this mutation in diffuse gliomas along multiple midline locations (4), (iv) the definition of molecular features to diagnose IDH-wildtype glioblastomas, specifically gains of chromosome 7, loss of chromosome 10, epidermal growth factor receptor
(EGFR) amplification and telomerase reverse transcriptase (TERT) promoter mutation (5). Also, rarer diagnostic entities were subsequently described, such as histone H3 G34R/V-mutant highgrade gliomas which are clinically and biologically distinct from H3 K27M-mutant tumours (6). The introduction of DNA methylation profiling has led to a further progress in the way neuropathologists approach diagnosis and prognostication of a wide range of adult and paediatric CNS tumours (7-10). This review focuses on biomarker-led classification of gliomas in adults. It is the aim of this review to provide guidance for an evidence-based, practical approach to diagnose intrinsic adult brain tumours using conventional molecular tests and methylation array profiling. 


\section{Methodologies for Integrated Histo-Molecular Diagnosis}

Immunohistochemical Stainings remain the diagnostic mainstay of histopathology laboratories. Whilst traditionally a range of lineage markers such as glial fibrillary acidic protein (GFAP) (11), S100 (12), synaptophysin (13), cytokeratins (14), or CD (cluster of differentiation) antigens (15) provided helpful guidance to pathologists to determine the lineage of neoplasms, they have not allowed for a refined classification or diagnostic

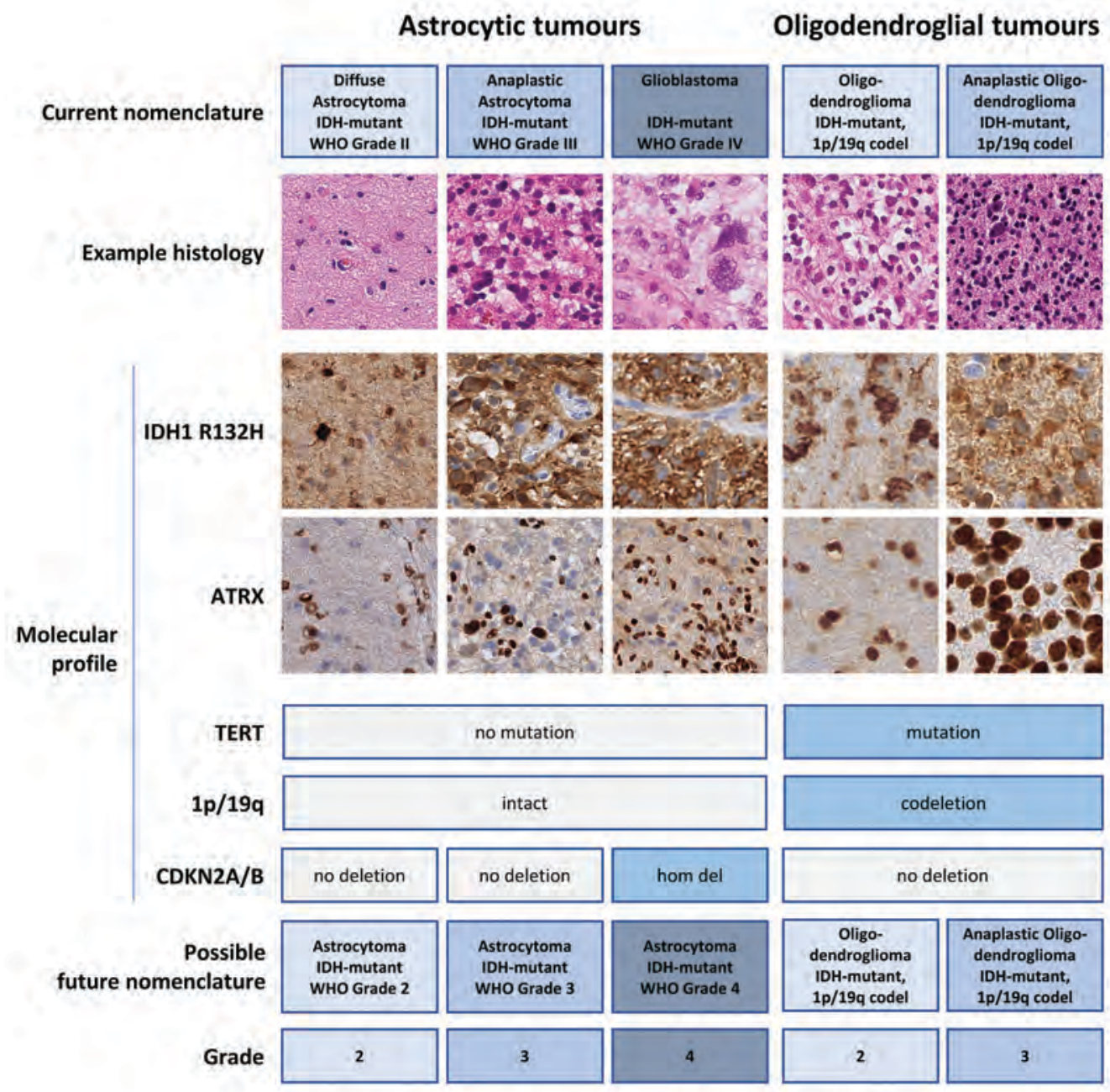

Figure 1. Histology and Molecular Pathology of IDH-mutant Gliomas. The left part of the panel shows the three malignancy grades of IDH-mutant astrocytomas (Grades II, III, IV) and the right part of the two malignancy grades of oligodendrogliomas (Grades II and III). Top row, current nomenclature comprising astrocytoma, anaplastic astrocytoma and glioblastoma, IDH-mutant, and oligodendroglioma and anaplastic oligodendroglioma IDH-mutant and 1p/19q codeleted. The second row shows typical histologies representative of the tumour types and grades. The third row shows the most common IDH mutation (IDH1 R132H) detected by immunostaining. For complete workup however tumours negative for this mutation should be followed up by sequencing. The other relevant diagnostic marker is the expression of ATRX. In most IDH-mutant astrocytic tumours, nuclear ATRX expression is lost in tumour cells but retained in endothelial cells, and non-neoplastic cells of the underlying CNS. The boxes below show the typical molecular profiles. TERT promoter mutation and ATRX mutation are mutually exclusive, thus non-mutant in astrocytomas and mutant in oligodendrogliomas. TERT promoter sequencing can therefore be useful in a small number of IDH-mutant astrocytomas where ATRX protein is retained in tumour cell nuclei despite a gene mutation. 1p/19q is by definition intact in astrocytomas and co-deleted in oligodendrogliomas (28). CDKN2A/B is a prognostically relevant in IDH-mutant astrocytomas (29). Bottom rows: proposed grading and prognostication of IDH-mutant gliomas, adapted from the proposed grading schemes $(28,29,86)$. 
stratification of tumours arising from progenitors of the central nervous system. For example, GFAP is expressed not only in mature astrocytes but also in a wide range of neural stem and progenitor cells (16). GFAP is expressed in multiple types of glial or glioneuronal tumours (11) and therefore can give only a first indication of the lineage of a tumour but does not allow further prognostication. The discovery of pathogenic and diagnostic point mutations led to the development of mutation-specific antibodies, for example against IDH1 R132H (17), BRAF V600E $(18,19)$, or histone H3 K27M (4), enabling rapid and reliable identification of these mutations and subsequent classification, grading and thus, prognostication (Figure 1,4). Other immunostainings to detect diagnostically relevant biomarkers are alpha-thalassemia X-linked mental retardation (ATRX) in a range of tumours of the CNS (Figure $1,4)$ and elsewhere, or INI1/SMARCB1 to identify loss of nuclear expression due to an inactivating mutation for example in atypical teratoid/rhabdoid tumour (AT/RT) $(20,21)$.

Fluorescent or Chromogenic in Situ Hybridisation (FISH, CISH) have been used for several decades to identify copy number changes (such as EGFR amplification, $1 \mathrm{p} / 19 \mathrm{q}$ codeletion, MYC amplification) on tissue sections. For that reason, these techniques are popular with pathologists as the sample can be analysed microscopically. Probes are usually expensive and with the decreasing cost of parallel sequencing technologies they gradually become economically less viable, but remain important methods in departments where next generation sequencing is not available.

Sanger Sequencing is an economical and highly informative test for those mutations that cannot be detected with a mutation-specific antibody. For example, the TERT promoter mutation (Figure 1), diagnostically relevant in IDH-mutant oligodendrogliomas, IDH-wildtype glioblastomas (Figure 3 ) and prognostically relevant in meningiomas, can only be detected by DNA-based methods. Whilst an antibody can be used to detect the most common IDH mutation (IDH1 R132H, Figure
1 ), the remaining $10 \%$ can only be detected with Sanger sequencing of the IDH1 the IDH2 genes.

Multiplex Ligation-Dependent Probe Amplification (MLPA) is a PCR-based technology requiring a thermocycler and capillary electrophoresis equipment and is thus an economical alternative to next-generation sequencing but has the disadvantage of a lack of flexibility. The disadvantage of MLPA assays is that they are pre-developed and require major validation steps following modification.

Next Generation Sequencing (NGS) is based on the Sanger sequencing technology and results in single-base readout. It covers millions of fragments in parallel (thus often referred to as (massive) parallel sequencing). The advantage of this technology is the generation of a wealth of information on multiple genes, but it requires infrastructure for data storage and the knowledge to read and interpret the substantial datasets. The generation of NGS data requires expensive equipment in core facilities.

Methylation Arrays interrogate methylation on $\mathrm{CpG}$ sites and return datasets that have been used to develop a methylation-based classification tool. DNA methylation is a form of an epigenetic change, which can be considered as surrogate markers for a combination of a cell of origin (reflecting location and time) and a mutation. These methylation profiles can be interrogated by machine learning algorithms and have led to the definition of methylation classes. These methylation classes partly overlap with histological tumour types defined by the WHO classification, but for some tumours, entirely distinct methylation classes have been defined and novel tumour entities have emerged (7-10). This approach will significantly influence the upcoming edition of the WHO 2020/2021 classification. The technology requires commercial micro-array chips (currently Illumina 850k EPIC arrays), a laboratory setup to perform bisulfite conversion of DNA and a relatively expensive chip reader. A widely used analysis platform is hosted by the German Cancer Research Centre (DKFZ) www. molecularneuropathology.org and can currently be accessed free of charge. 


\section{IDH-Mutant Gliomas: Oligodendrogliomas and Astrocytic Tumours}

Mutations in the IDH1 and IDH2 genes were discovered in the context of a whole-genome sequencing study on glioblastoma $(1,22)$. Mutations in the IDH1 gene were identified small subgroup of what was known at the time as "secondary GBM", i.e. arising from lower grade astrocytomas. Subsequently, large cohorts of astrocytomas, oligodendrogliomas and the now discontinued oligoastrocytoma were sequenced for the presence of IDH1

A

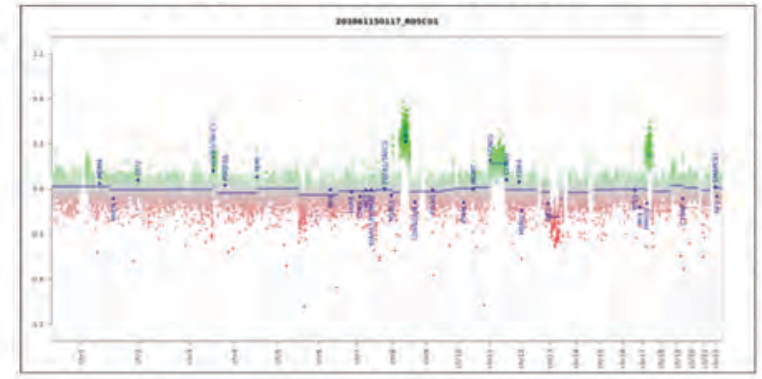

Astrocytoma

favourable

Prognosis

(Grade II)

B

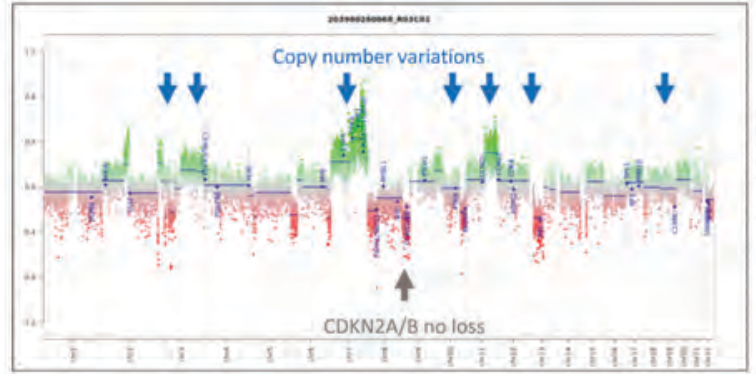

\section{Astrocytoma}

Intermediate

Prognosis

(Grade III)

C

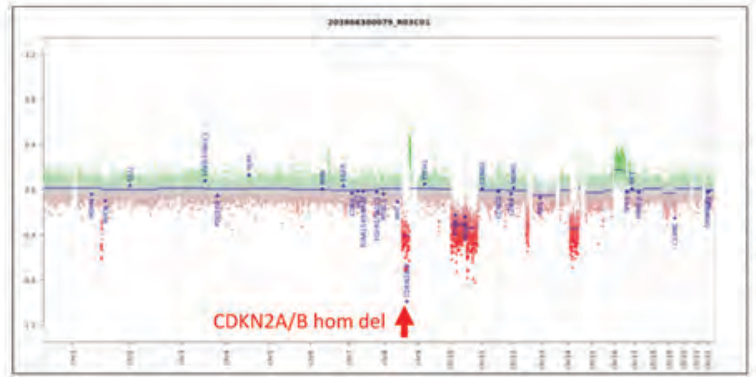

Astrocytoma

poor prognosis

(GBM-IDH,

Grade IV)

D

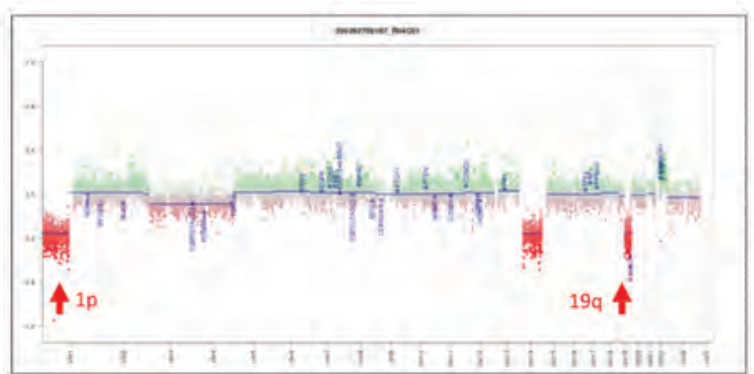

Oligodendroglioma

Grade II and III

Figure 2. Copy Number Profiles of IDH-mutant Gliomas. A, relatively flat copy number profile of low-grade IDH-mutant astrocytomas. B, multiple copy number changes with multiple gains and losses, but no CDKN2A/B deletion are indicative of a higher recurrence risk (29). $C$, the presence of a CDKN2A/B homozygous deletion indicates a high recurrence risk, regardless of the presence of microvascular proliferations and necrosis (29). D, Oligodendrogliomas are characterised by the characteristic $1 p / 19 q$ codeletion. Additional copy number alterations can occur but there is no established molecular profile discriminating grade II from grade III. Currently, oligodendrogliomas are distinguished from anaplastic oligodendroglioma by morphological criteria. 
and IDH2 mutations $(9,23)$. Importantly, it was soon established that $1 \mathrm{p} / 19 \mathrm{q}$-codeleted oligodendrogliomas were invariably IDH-mutant, leading to the subsequent definition of the "oligodendroglioma, IDH-mutant and 1p/19q-codeleted" as diagnostic entity (24) (Figure 1,2). The remainder of IDH-mutant gliomas had an astrocytic morphology, and it was soon established that the concomitant loss of ATRX expression was a defining feature of astrocytomas (24) (Figure 1). Importantly, the previously known group of oligoastrocytoma could be resolved into either oligodendroglioma or astrocytoma, and thus the diagnosis of oligoastrocytoma has been discontinued $(25,26)$. As a result, two major IDH-mutant tumour types exist, oligodendroglioma with IDH mutation, $1 \mathrm{p} / 19 \mathrm{q}$ codeletion and TERT promoter mutation (27), and the astrocytoma with IDH mutation, ATRX mutation and p53 mutation (28) (Figure 1). The distinction of oligodendroglioma from the anaplastic oligodendroglioma still relies on the identification of morphological features (microvascular proliferations, brisk mitotic activity, necrosis). IDH-mutant astrocytomas can be further stratified not only by histological features but also by the presence of homozygous loss of cyclin-dependent kinase inhibitor 2A/B (CDKN2A/B) $(29,30)$ (Figure 2). The presence of this mutation is a better predictor of survival than the presence of microvascular proliferations or necrosis. This results in a proposed histo-molecular grading scheme for IDH-mutant astrocytomas ranging from grade II to grade IV. It has been recommended to phase out the term IDH-mutant glioblastoma and to replace it with astrocytoma grade IV to indicate a distinctive biological class of brain tumours (28). Figure 1 illustrates the diagnostic algorithm and grading scheme in IDH-mutant gliomas.

\section{IDH-Wildtype Gliomas: The Spectrum of Glioblastomas and Their Precursors}

The glioblastoma multiforme (GBM) is the most common malignant brain tumour in adults. The designation as IDH-wildtype glioblastoma was established in parallel to the distinction of the
IDH-mutant counterparts (31). Subsequently, it was discovered that not all glioblastomas present histologically with high-grade features at the time of diagnosis (Figure 3). Instead, it was recognised that many tumours that presented clinically and histologically as diffuse astrocytomas in fact were early forms of glioblastoma (32). This recognition was based on the presence of characteristic diagnostic features such as a combination of a TERT promoter mutation, EGFR amplification, chromosome 7 gain, chromosome 10 loss, in the absence of an IDH mutation (8) (Figure 3). Ultimately, this recognition has led to a recommendation by the cIMPACT-NOW consortium to identify all tumours with some or all of the above features as glioblastoma, IDH-wild-type, regardless of the histological appearance (33).

\section{Histone-Mutant Gliomas}

These gliomas are defined by specific mutations, histone H3 K27M or histone H3 G34R. These two mutations are associated with entirely distinct clinical, imaging, histological and molecular features (Figure 4). H3 K27M mutations were described in two large studies $(3,34)$, which triggered subsequent research into chromatin modifiers in brain tumour pathogenesis (34) and led to the identification of potential therapeutic targets $(35,36)$. Initially the H3 K27M mutation was identified in diffuse infantile pontine gliomas (DIPG) but with the commercial availability of mutationspecific antibodies (Figure 4A), and the recognition that these tumours are located in midline structures of the central nervous system (spinal cord, pons, thalamus) these tumours were increasingly found also in adults (37). One important recognition is the association of the K27M mutation with midline location and poor clinical outcome, thus mandating a WHO grade IV for $\mathrm{H} 3 \mathrm{~K} 27 \mathrm{M}$ midline gliomas (38). However, rarely also other intrinsic tumour types, specifically ependymoma, ganglioglioma or pilocytic astrocytoma can carry an H3 K27M mutation but are explicitly excluded from the grading and typing scheme of H3 K27Mmutant midline gliomas (39-41). 


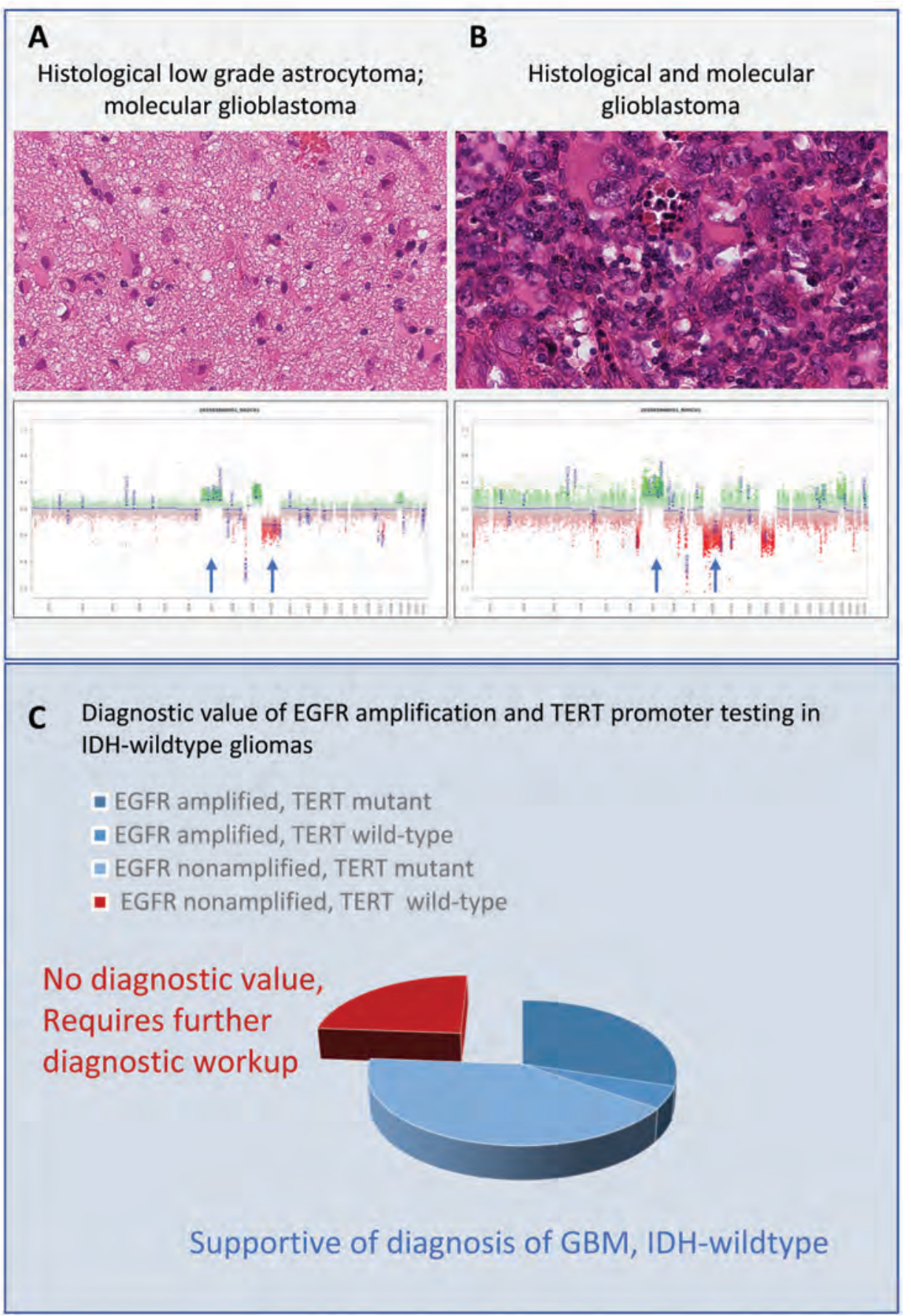

Figure 3. Histological Presentation of IDH-wildtype Glioblastomas Can Vary Significantly. A, in this example the histological features are those of a diffuse low-grade glioma and only molecular testing (for example EGFR amplification, TERT promoter mutation, and/or detection of chromosome 7 gain and chromosome 10 loss) can ascertain the diagnosis of a glioblastoma, IDH-wildtype (33). B, example of glioblastoma with histological high-grade presentation and characteristic copy number changes (7p gain, 10q loss). Both glioblastomas show a CDKN2A/B homozygous deletion which however have no prognostic value in this tumour entity. C, the majority of glioblastomas can be diagnosed by the presence of EGFR amplification and or TERT promoter mutation. If neither TERT promoter mutation nor EGFR amplification can be identified in an IDH-wildtype glioma, further diagnostic tests (copy number profile (A, B), methylation array or next-generation sequencing should be performed in particular for those tumours presenting with histological low-grade features (32). 
A

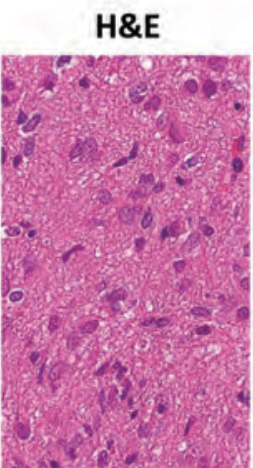

H3 K27M


B



Figure 4. Histone Mutant Gliomas Comprise two Biologically, Clinically and Histologically Distinct Entities. A, the H3 K27Mmutant glioma presents as diffuse astrocytoma, often with no apparent high-grade features. The morphology is that of diffuse glioma but the use of the antibody against the $\mathrm{H} 3 \mathrm{~K} 27 \mathrm{M}$ mutation allows reliable diagnosis of these tumours (38). A proportion of these tumours show ATRX loss. Resident endothelial and glial cells show retained ATRX expression. B, the H3 G34R (rarely also G34V) mutant glioma shows a very high cellularity, usually very little or no GFAP expression and a loss of ATRX expression in tumour cells. The remaining positive nuclei are those of endothelial cells. Ki67 labelling indicates the extremely high proliferation of these tumours. In contrast to the K27M-mutant tumours, G34R-mutant gliomas are hemispheric. 
Gliomas with H3 G34R/V mutations have discrete clinical presentations (age, location, survival) and molecular features (methylation profiles, expression signatures, and mutational profiles), suggesting that they are arising from a different cell of origin and are essentially distinct diseases $(42,43)$ (Figure 4B). An important clinical difference to $\mathrm{H} 3$ $\mathrm{K} 27 \mathrm{M}$-mutant gliomas is the presentation as hemispheric, often well demarcated primitive tumours (6), but occasionally a diffusely infiltrative hemispheric lesions encompassing multiple lobes, a feature previously referred to as gliomatosis cerebri.

\section{Glial and Glioneuronal Tumours with MAP-Kinase and MYB/MYBL Alterations}

The recognition of alterations in the MAP kinase pathway, predominantly through mutations of BRAF, and other MAP kinase pathway members has had some diagnostic benefit, but more importantly also therapeutic implications. The detection of a BRAF mutation is diagnostically helpful, but does not define a specific tumour entity (Figure 5). Approximately $60 \%$ of pleomorphic xanthoastrocytoma, 30\% of ganglioglioma (a range between $10 \%-60 \%$ has been reported, depending on age and anatomic location of the tumour (44)), and less than $5 \%$ of pilocytic astrocytomas carry a BRAF V600E mutation, which therefore is diagnostically neither specific nor is the absence of the mutation informative (Figure 5). Importantly, the detection of a BRAF V600E mutation is also not predictive of the prognosis, as it can occur in a wide range of tumours with low recurrence risk (gangliogliomas), intermediate recurrence risk (pleomorphic xanthoastrocytoma), or high recurrence risk (anaplastic pleomorphic xanthoastrocytoma with $\mathrm{CDKN} 2 \mathrm{~A} / \mathrm{B}$ homozygous deletion which may histologically overlap with the epithelioid GBM).

Gangliogliomas (Figure 5A) often present with a long-standing history of seizures. They grow relatively well demarcated, are occasionally calcified and are composed of dysplastic neuronal and glial cells. Gangliogliomas are characterised by alterations of the MAP kinase pathway showing BRAF, KRAS, RAF1, NF1, FGFR1, or FGFR2 mutations as pathogenic alterations (44, 45). Ganglioglioma correspond to WHO grade I. They can show some morphological overlap with other low-grade glioneuronal tumours, for example pleomorphic xanthoastrocytoma or DNET (46).

Pleomorphic Xanthoastrocytomas (PXA) (Figure 5B) most commonly affect children and young adults, but also can occur in patients in their 40s60s. These tumours often grow superficially and can form a cyst. Histologically, they may show a highly heterogenous picture with formation of giant astrocytes which can be lipidised (xanthomatous). PXA express GFAP and often also neuronal lineage markers such as neurofilaments and occasionally synaptophysin. The homozygous deletion of CDKN2A/B is a negative prognostic factor associated with more rapid recurrence (47). The detection of the BRAF mutation in PXA (described in up to $60 \%(2)$ ) is essential to provide guidance to oncologists for treatment options with BRAF antagonists, such as Vemurafinib or Dabrafenib $(48,49)$.

Pilocytic Astrocytomas (Figure 5C) are most commonly located in the posterior fossa (cerebellum) but hemispheric and midline forms exist. Morphologically, these forms are indistinguishable, but exhibit distinct methylation pattern which can be determined by methylation array analysis. For posterior fossa pilocytic astrocytoma, the most common molecular alteration is the fusion of BRAF with the KIAA 1549 gene (3 common breakpoints KIAA1549:BRAF exons 15:9, 16:11, 16:9 (50) and rarely 15:11 and 17:10 (51)). A large molecular study on more than 100 pilocytic astrocytomas showed additional alterations in other components of the MAP-kinase pathway, such as FGFR1, NTRK2, NF1, KRAS and PTPN11 (52). Amongst the group of pilocytic astrocytomas, there are three molecularly (mostly epigenetic) distinct types, with location in the cerebellum, midline and forebrain hemispheric (53). A separate biological entity with frequent loss of ATRX expression and CDKN2A/B homozygous deletion had previously been termed anaplastic astrocytoma with piloid features (Figure 5E) and the diagnosis of "High-grade astrocytoma with pi- 


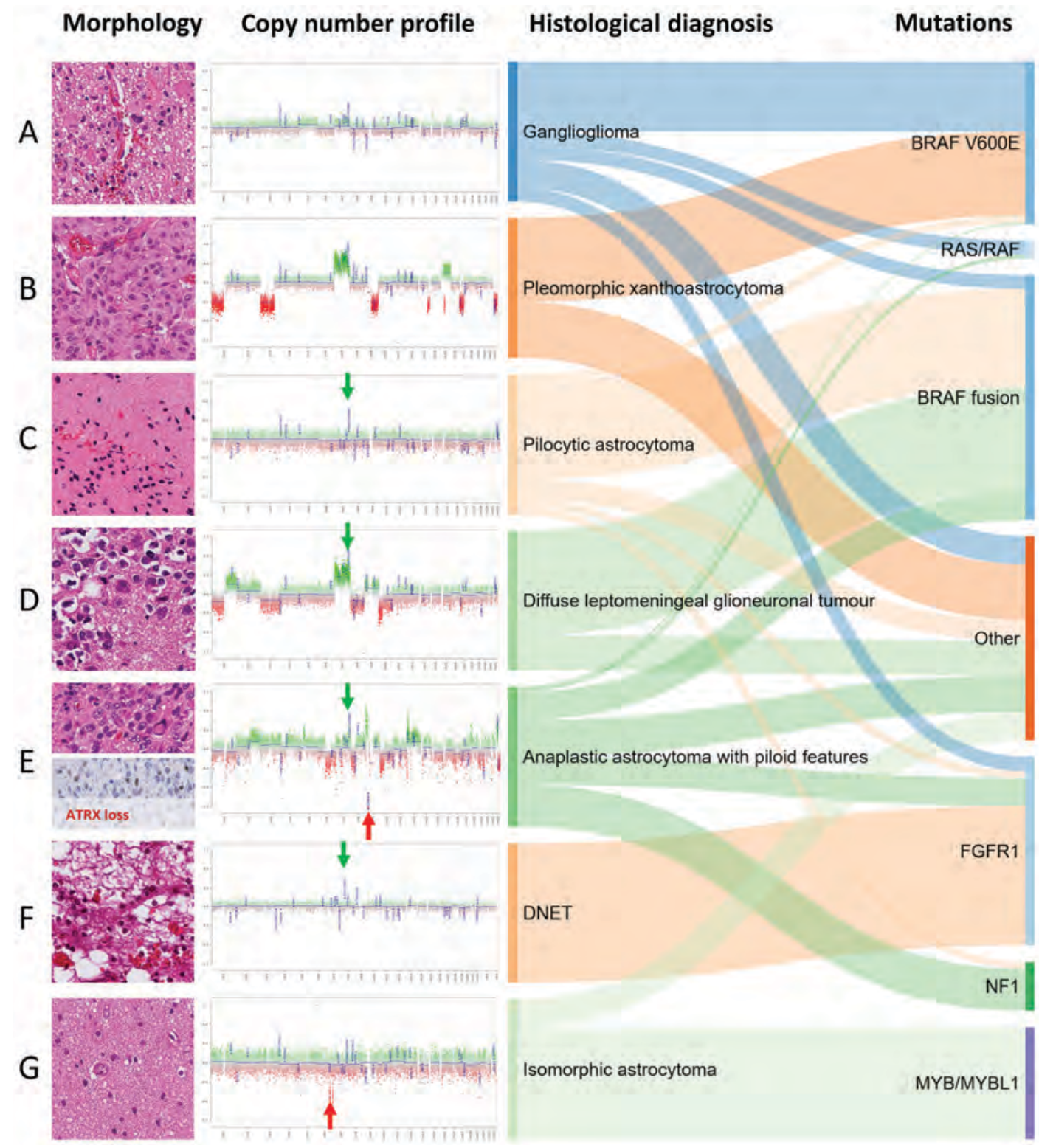

Figure 5. Morphology, Copy Number Profile and Frequently Associated Mutations in a Range of Glial and Glioneuronal Tumours. Tumour location and their association with certain mutations are helpful in the differential diagnosis of these tumour classes. A, the ganglioglioma has a characteristic morphology, a flat copy number profile and frequently a BRAF V600E mutation. B, the pleomorphic xanthoastrocytoma has a characteristic histology but transitional forms with similarities to gangliogliomas exist and can be resolved by methylation array analysis. The copy number profile typically shows some variability. The majority of PXA has a BRAF V600E mutation. C, the pilocytic astrocytoma has a BRAF duplication (fusion) in more than $70 \%$ of cases, which can be detected in the copy number profile or with specific fusion tests $(50,61)$. The remainder of the pilocytic astrocytomas have other MAP kinase pathway alterations. $\mathbf{D}$, the rare diffuse leptomeningeal glioneuronal tumour has a BRAF fusion and a $1 p$ deletion, sometimes also $1 \mathrm{p} / 19 \mathrm{q}$ codeletion, but strictly without IDH mutation, which discriminates it from the oligodendroglioma. E, a relatively recently established tumour class is the anaplastic astrocytoma with piloid features, characterised by BRAF fusion, CDKN2A/B homozygous deletion and frequent ATRX loss (54). F, The dysembryoplastic neuroepithelial tumour (DNET) has frequent FGFR fusions and otherwise a flat copy number profile. $G$, the isomorphic astrocytoma is characterised by mutations of MYB or MYBL which can be detected in copy number profiles (66). All tumours in this figure were confirmed by methylation profiling and tumours showed the corresponding copy number profile. 
loid features" has been put forward for the 2021 WHO classification. These tumours are predominantly located in the cerebellum, and form a distinct methylation class (54). These tumours have an unfavourable outcome compared to pilocytic astrocytomas, but better than glioblastoma.

The Diffuse Leptomeningeal Glioneuronal Tumour (DLGNT, Figure 5D) is an entity that is well characterised molecularly but may be less recognised in neuropathological differential diagnosis and thus may be underdiagnosed. Originally described as mostly in leptomeningeal and thus superficial locations, it has been recognised that they can also originate from midline structures and only secondarily spread to hemispheric structures, and other reports suggest isolated hemispheric origin (55). Histologically they appear as "neurocytic" tumours, similar to oligodendroglioma or neurocytoma (56). They can carry microvascular proliferations. All DLGNT carry a 1p loss, often in combination with a BRAF fusion and occasionally with additional $19 q$ loss (57). However, they can be discriminated from $1 \mathrm{p} / 19 \mathrm{q}$-codeleted oligodendrogliomas by their definite absence of IDH mutations. Methylation profiling of a large cohort identified two distinct methylation profiles, separating a predominantly paediatric (DLGNT-MC-1) from an adult subgroup DLGNT-MC-2 (57).

Dysembryoplastic Neuroectodermal Tumours (DNET) (Figure 5F) grows in nodular formations close to the cortical surface. A characteristic feature is the glioneuronal element composed of bundles of glial cells, lined by small neurocytic tumour cells. These structures surround myxoid lakes, containing occasional resident neurons, which are aptly named "floating neurons". A proportion of DNET carry molecular alterations in FGFR (point mutations and fusions) (58) but these are not specific for this tumour entity, as they have been identified in a wider range of low-grade and high-grade glial neoplasms $(52,59-61)$. Previous reports of the presence of BRAF V600E mutations in DNET (62-64) may have been based on a diagnostic overlap with gangliogliomas, as discussed in a recent comparative review (46).

Isomorphic Gliomas (Figure 5G) belong to the group of neoplasms with MYB/MYBL mutations and are histogenetically and molecularly unrelated to tumours with MAP kinase pathway alterations (61). Histologically, these tumours have a very low cellular density with a diffuse, compact, fibrillary matrix and lack a distinctive histological pattern (Figure 5G). Sometimes they can be difficult to be discriminated from CNS white matter. Whilst histological features and immunohistochemical profiles are indistinctive, isomorphic gliomas carry diagnostically relevant copy number alteration, fusion or rearrangement on the MYB or MYBL1 loci (65). The methylation profile of these tumours is distinct. (66).

\section{Ependymal Tumours}

Ependymomas (Figure 6) were for many years known for their poor correlation between histological appearance, grading and clinical outcome. A wealth of studies with genome-wide profiling of genome, transcriptome and methylome of ependymal tumours have provided a deep insight into the molecular pathogenesis, and at the same time resulted in the discovery of useful biomarkers that can be implemented in standard histological settings. In parallel, the characterisation of methylation profiles has resulted in the identification of 10 biological subclasses (" $3+3+4$ ") that can be characterised by a combination of location, molecular profile and to some extent, age of onset (67).

This classification describes 3 supratentorial, 3 infratentorial and 4 spinal forms (Figure 6). In the supratentorial compartment, the 3 molecular types are RELA fusion, YAP fusion and subependymoma. In the infratentorial compartment, the 3 molecular types, ependymoma type A, B, and subependymoma. The four molecular subtypes in the spinal compartment are the classical ependymoma, subependymoma, myxopapillary ependymoma (67) and the recently identified very rare ependymoma with MYCN amplification (68).

The majority of the subclasses show a $100 \%$ 5-year survival (Figure 6). The subclasses with poor survival are the supratentorial ependymoma with RELA fusion, the infratentorial ependymoma type A, and the spinal cord ependymoma with MYCN amplification (68-71). 


\section{Location}

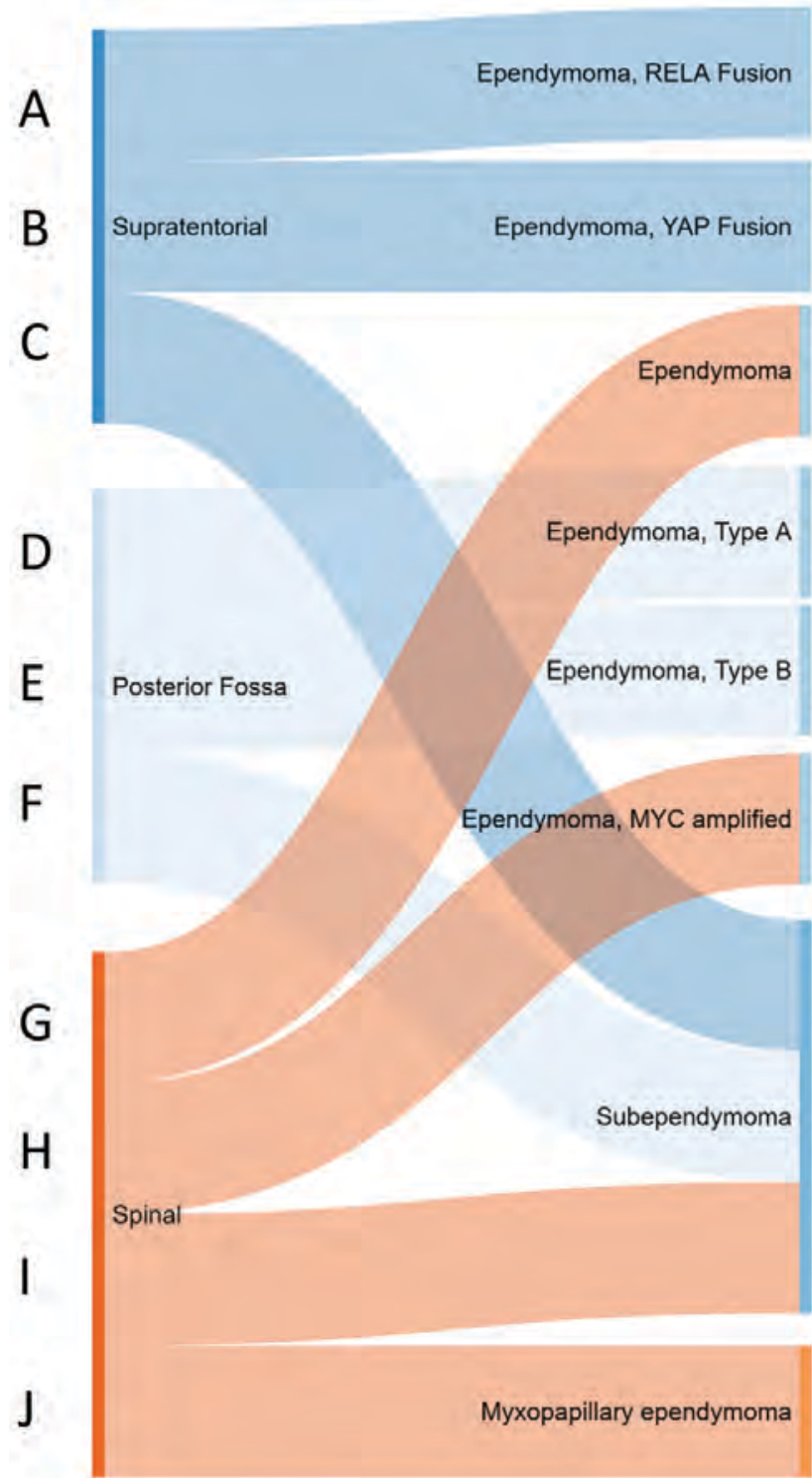

Molecular class


100



100

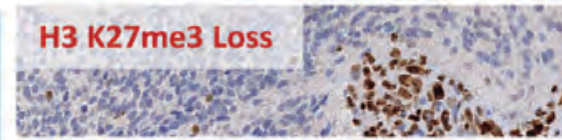

70



100

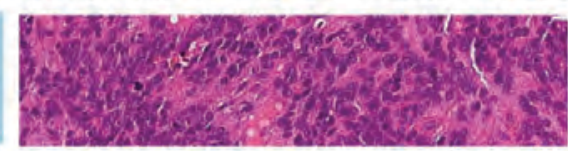

70

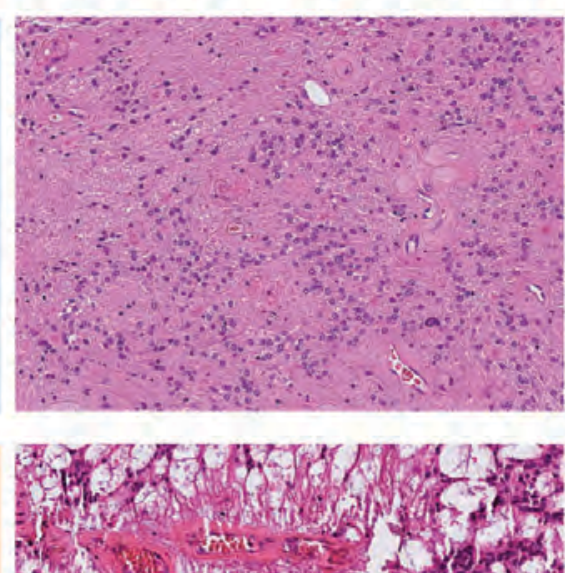

100

Figure 6. Molecular Classes, Histology and Survival of Ependymomas. 10 distinct molecular groups exist (67, 68, 87). In the supratentorial space ( 3 groups, A, B, C) ependymoma with RELA (A) or YAP fusion (B) present histologically as highgrade ependymoma. Instead, the subependymoma $(C)$ is histologically benign and histologically indistinguishable, but molecularly distinct between supratentorial (C), infratentorial (F), and spinal (I) locations. In the posterior fossa (3 groups) the ependymoma type A (D) can be diagnosed by the loss of H3 K27me3 expression in tumour cell nuclei (retained expression in tumour vessels) whilst type $B(E)$ has a retained expression of this marker. In the spinal compartment (4 groups), the classic ependymoma $(G)$ appears histologically benign. Instead, the recently identified, rare anaplastic ependymoma with MYC amplification (68) (H) is highly malignant and does not always show the typical ependymal morphology. I, the subependymoma occurs in the cervical spinal cord, and is histologically and clinically benign. J, the myxopapillary ependymoma typically occurs in the cauda equina, and is histologically bland in most instances but a recent study indicates increased recurrence risk (79). The left part of the graph indicates location of the tumour, the centre the molecular class and the associated typical histology. On the right, 5 year survival in percent. 
Molecular features and methylation profiles of ependymomas the classification of ependymal tumours not only relies heavily on, but also can be accomplished easily with, methylation arrays (72). The description of methylation classes is formed of acronyms incorporating the tumour type (EPN= ependymoma), location (ST, PF, and SP for supratentorial, posterior fossa and spinal, respectively) and molecular or histological subtype.

In the supratentorial space, the 3 types of ependymoma are the clinically benign subependymomas (EPN_ST_SE) and ependymomas of WHO grades II and III, with either the RELA fusion (EPN_ST_RELA) with a poor 5-year survival or the YAP 1 fusion (EPN_ST_YAP1) with a relatively good 5-year survival (73). Five fusion genes between YAP1-MAMLD1 and YAP1-FAM118B have been described, but the pathogenic mechanism has yet to be determined. More than two-thirds of supratentorial ependymomas contain oncogenic fusions between RELA (effector of canonical NF$\kappa \mathrm{B}$ signalling), and a gene on chromosome 11, C11orf95. C11orf95-RELA fusion proteins translocate to the nucleus and activate NF- $\kappa \mathrm{B}$ target genes (74) and this translocation can be detected by immunostaining for the $\mathrm{p} 65$ protein (75).

In the posterior fossa there is the clinically benign subependymoma EPN_PF_SE occurring mostly in middle-aged patients, and the ependymomas subtype A (EPN_PF_A) occurring in young children with poor prognosis and the ependymoma subtype B (EPN_PF_B) occurring in older children, teenagers and adults, with a more favourable prognosis $(76,77)$. An important discovery was the downregulation of the trimethylated form of $\mathrm{H} 3 \mathrm{~K} 27 \mathrm{M}$ (H3 K27me3) in EPN_ PF_A (H3 K27me3 loss of expression) which enables a diagnostic distinction from EPN_PF_B H3 K27me3 retained expression) (78) (Figure 6 D, E).

Spinal Ependymomas again comprise the benign sub ependymoma (EPN_SP_SE, histologically identical, but molecularly distinct from supratentorial and infratentorial counterparts). This tumour usually occurs in the upper spinal cord in adults. The generally, but not always benign (79) myxopapillary ependymoma (EPN_SP_MPE) is usually located in the cauda equina and occurs in adults. The classical ependymoma (SP_EPN) can occur along the entire spinal cord and an aggressive subtype, molecularly distinct from SP_EPN is the MYCN amplified ependymoma (SP_EPN_MYC).

Despite the significant advances in molecular profiling and classification of ependymal tumours (80), the treatment options have so far not developed at the same pace, and targeted therapies have yet to be developed. Current guidelines recognise molecular subgroups but cannot offer options for personalised treatment $(70,71)$.

\section{The Use of Methylation Array Profiling in Diagnostic Neuropathology}

The use of methylation array profiling to establish the histogenesis, molecular profile, and in some instances prognostication of brain tumours requires a number of considerations to ensure resources are invested adequately, and the outcome meet the expectations of neuropathologists, oncologists, surgeons, and of course, patients.

In previous publications $(7,9)$ we established 7 broad reasons for using methylation arrays. Over the last 5 years we have analysed over 1500 brain tumour samples with this technology, mostly for diagnostic, and occasionally also for research and quality assurance purposes. Table 1 provides examples for these distinct clinical rationales. Once the rationale for the use is established, there are several different outcomes of the molecular tests, listed in Table 2. The relationship between test rationale and readout/outcome is shown in Figure 7. An important factor for a successful readout of this test is the calibrated score, a "probability" indicator of the match of the profile of a sample to the reference set. In our practice we are using a score of 0.84 as a cut off to rely on the computed methylation class. An important additional information derived from the array chips is the copy number profile that can independently verify certain diagnoses, such as $1 \mathrm{p} / 19 \mathrm{q}$ codeletion in oligodendrogliomas, chromosome 7 gain and chromosome 10 loss in IDH-wildtype glioblastoma, BRAF 


\section{Reason for testing}

\section{Test outcomes}

-(1) small biopsy or nonrepresentative sample;: 12

\section{(1) confirmation of diagnosis: 85}

\section{(2) unusual histology, location, demographics: 108}

(3) non-specific histology: 146

(2) refinement of diagnosis: 429

(4) IHC, sequencing, or copy number assay ambiguous: 90

= (5) Confirmation of rare, unusual or interesting histo-molecular results: 15

(6) Research sample, for stratification or subclassification: 77

(7) Establish methylation class for histologcally defined entities, e.g. Medullo, ependymoma, etc: 248

(3) establishing new diagnosis: 152

(4) misleading profile: 9

(5) Non-contributory profile: $21=$

Figure 7. Rationale for Methylation Profiling and Test Outcomes in Our Clinical Practice. Over 1500 tumours were tested between March 2015 and October 2020 for diagnosis, research and quality assurance. Of these, 696 had a calibrated score of 0.84 and higher and are included in this alluvial diagram. The left side shows the reason for testing, as described in table 1. The right side shows the test outcome, as described in table 2 . This diagram illustrates that the majority of tumours with a unusual location and demographics (2) or with non-specific histology (3) resulted in a refined or newly established diagnosis. It also shows that the majority of tests performed to establish methylation class of histologically defined entities (7) had a refinement of the diagnosis, whilst a small proportion of tumours with a presumed firm diagnosis returned a (usually unexpected) new diagnosis. This graph also includes research samples where the diagnosis was predominantly confirmed, or refined, but occasionally a new diagnosis was established. The remaining tumours with a calibrated score of lower than 0.84 were not included in the analysis. With a decreasing calibrated score, the proportion of misleading or noncontributory profiles increases.

duplication in pilocytic astrocytomas or DLGNT, SMARCB1 loss in AT/RT.

In our practice the combination of biopsy size, tumour location, treatment options and patient age are factors that determine our threshold to perform methylation arrays. In particular small biopsies (usually from delicate brain regions such as optic tract, pineal gland, brainstem, spinal cord or thalamus) undergo only very limited testing with
IHC (context -dependent, for example H3 K27M, IDH, ATRX, INI1), and avoiding stereotypically used stains of often limited diagnostic value such as Ki67, GFAP, synaptophysin, or vimentin to preserve tissue for the far more informative methylation array. We recommend to carefully consider and minimise the use of such markers in particular in small biopsies and encourage to consider referral for methylation arrays. 
Table 1. Rationale for the Use of DNA Methylation Profiling for Brain Tumours*

\begin{tabular}{|c|c|c|}
\hline \multicolumn{2}{|c|}{$\begin{array}{l}\text { Reason for using } \\
\text { classifier }\end{array}$} & \multirow{2}{*}{$\begin{array}{l}\text { Examples } \\
\text { Even though it may appear counterintuitive, an important reason for using methylation arrays is a small } \\
\text { biopsy. Typically, biopsies in this category are from difficult locations to establish a clinical diagnosis with } \\
\text { minimal invasiveness and risk, for example, optic pathway, midline location, brain stem, spinal cord). A } \\
\text { minimal number of immunostainings (e.g., IDH R132H, histone K27M, ATRX, SMARCB1) can be performed } \\
\text { to preserve tissue for subsequent array analysis. Nearly all small biopsies with indistinctive histology } \\
\text { undergo methylation profiling in our practice. }\end{array}$} \\
\hline 1 & $\begin{array}{l}\text { Small biopsy or } \\
\text { nonrepresentative } \\
\text { sample }\end{array}$ & \\
\hline 2 & $\begin{array}{l}\text { Unusual histology, } \\
\text { location, } \\
\text { demographics }\end{array}$ & $\begin{array}{l}\text { Intrinsic tumours with unusual or distinctive histological patterns, in any age group, which are not } \\
\text { diagnostically intuitive. These can turn out to be rare entities (such as hemispheric DLGNT, RELA fusion } \\
\text { ependymoma, spindle cell tumours) }\end{array}$ \\
\hline 3 & $\begin{array}{ll}\mathrm{Nc} \\
\mathrm{hi}\end{array}$ & $\begin{array}{l}\text { One of the most common indications for the use of methylation arrays: For example, high-grade or low- } \\
\text { grade tumours with no distinctive histology, which are negative for common biomarkers (IDH, BRAF, } \\
\text { histone, TERT, EGFR). The outcome (methylation profile) of many high-grade tumours with indistinctive } \\
\text { histology is however glioblastoma, IDH-wildtype. Typical outcomes in low-grade gliomas are pilocytic } \\
\text { astrocytoma, isomorphic glioma, PXA, DNET, or ganglioglioma, but also the histologically low-grade } \\
\text { appearing GBM, IDH-wildtype (Figure 3). }\end{array}$ \\
\hline 4 & $\begin{array}{l}\text { sequencing, or } \\
\text { biguous }\end{array}$ & $\begin{array}{l}\text { Ambiguous copy number results include inconclusive } 1 \mathrm{p} / 19 \mathrm{q} \text { codeletion tests, failed sequencing results } \\
\text { for IDH, TERT, BRAF, false positive EGFR test results. Methylation arrays provide an independent evaluation } \\
\text { of such tumours. This is sometimes the case with tumours with ATRX loss, and no detection of IDH or } \\
\text { histone mutations. }\end{array}$ \\
\hline 5 & $\begin{array}{l}\text { Confirmation of } \\
\text { rare, unusual or } \\
\text { interesting histo- } \\
\text { molecular results }\end{array}$ & $\begin{array}{l}\text { This is a relatively rare indication, for example a histone K27M-mutant glioma seemingly occurring in a } \\
\text { lateral localisation, IDH mutant gliomas in the posterior fossa, rosette-forming glioneuronal tumour in a } \\
\text { spinal location, chordoid gliomas, etc. }\end{array}$ \\
\hline 6 & $\begin{array}{l}\text { Research sample, } \\
\text { for stratification or } \\
\text { subclassification }\end{array}$ & $\begin{array}{l}\text { his category is used for research samples. Often such tumours have already undergone a stratification by } \\
\text { her means, for example selection of a range of IDH-mutant or IDH-wildtype gliomas in a research study. }\end{array}$ \\
\hline 7 & $\begin{array}{l}\text { Establish } \\
\text { methylation class } \\
\text { for histologically } \\
\text { defined entities. }\end{array}$ & $\begin{array}{l}\text { Tumours falling in this category are usually diagnostically relatively straightforward. Typically, these include } \\
\text { medulloblastomas, ependymomas, and more recently also meningiomas. The methylation profiling is } \\
\text { performed for clinical and treatment stratification. However profiling of such tumours can occasional } \\
\text { reveal an incorrect assumption of a tumour type, resulting in "establishing a new diagnosis" (Figure 7). }\end{array}$ \\
\hline
\end{tabular}

'The left column indicates the reason for using the classifier (following the categorisation from previous publications $(7,9)$ ) and the right column gives typical examples from clinical practice.

Table 2. Categories of Outcomes from the DNA Methylation Classifier, Following the Definitions from Previous Publications $(7,9)^{*}$

\begin{tabular}{lll}
\hline Outcome & Examples \\
\hline 1 & $\begin{array}{l}\text { Confirmation } \\
\text { of diagnosis }\end{array}$ & $\begin{array}{l}\text { Confirmation of the differential diagnosis of a histologically diagnosed glioblastoma, pilocytic astrocytoma or } \\
\text { low-grade glial or glioneuronal tumours (ganglioglioma, DNET, rosette-forming glioneuronal tumour, etc.). }\end{array}$ \\
\hline 2 & $\begin{array}{l}\text { Refinement } \\
\text { of diagnosis }\end{array}$ & $\begin{array}{l}\text { Typically these include entities which have been correctly diagnosed but require molecular stratification, such } \\
\text { as the molecular subtype of meningioma, ependymoma or medulloblastoma. }\end{array}$ \\
\hline 3 & $\begin{array}{l}\text { Establishing } \\
\text { new diagnosis }\end{array}$ & $\begin{array}{l}\text { Most commonly these are biopsies of small size or with non-specific histology which have been diagnosed as } \\
\text { "diffuse glioma, NOS", classified for example as "ependymoma, RELA fusion", "pilocytic astrocytoma hemispheric } \\
\text { type","ganglioglioma", etc. }\end{array}$ \\
\hline 4 & $\begin{array}{l}\text { Misleading } \\
\text { profile }\end{array}$ & $\begin{array}{l}\text { Misleading profiles are typically associated with a low calibrated score. They occur in cases which do not } \\
\text { correspond to establish methylation classes, or in cases with low DNA content, or poor DNA quality. Figure 7 } \\
\text { shows only few such examples as only cases with a calibrated score of 0.84 and higher were included. }\end{array}$ \\
\hline 5 & $\begin{array}{l}\text { Non- } \\
\text { contributory } \\
\text { profile }\end{array}$ & $\begin{array}{l}\text { This can occur in problematic biopsies with low tumour content (classified as CNS tissue), or in samples } \\
\text { with significant reactive changes (tumour inflammation), classified as "reactive tumour micro environment". } \\
\text { A major proportion of tumours with this outcome were associated with the testing rationale of "unusual } \\
\text { histology, location and demographics" (Table 1 and Figure 7). These often result in a low calibrated score due } \\
\text { to a mismatch to any of the currently established methylation classes, i.e. may represent new, uncharacterised } \\
\text { entities. }\end{array}$ \\
\hline
\end{tabular}

"The examples are from our clinical practice and reflect typical outcomes. See Figure 7 for the relationship between testing rationale and outcome. 


\section{Summary and Conclusion}

This review provides an overview of the state-ofthe-art diagnostic approach to gliomas in adults. In particular, the diagnostic and prognostic criteria of IDH-mutant gliomas, the importance of the recognition of precursor forms of the IDHwildtype glioblastoma and the molecular analytics of a range of low-grade glial and glioneuronal tumours has been outlined. An important area is the molecular stratification of ependymal tumours which benefit from the availability of methylation arrays. Guidelines published by the Royal College of Pathologists provide diagnostic algorithms for an evidence-based, practical approach for the diagnosis of brain tumours https://www.rcpath. org/profession/guidelines/cancer-datasets-andtissue-pathways.html (accessed December 2020) (81). Further helpful guidance on the use of molecular biomarkers in brain tumour diagnostics is regularly published by the International Collaboration on Cancer Reporting ICCR http://www. iccr-cancer.org/ . Inevitably, this review had to exclude a number of diagnostically important areas in diagnostic neuropathology such as paediatric tumours, meningiomas and metastatic lesions. An excellent review on the application of molecular diagnostic strategies in clinical diagnostics of paediatric tumours has recently been published (82). Meningiomas have over the last few years moved into the focus of advanced molecular diagnostics and clinical decision making algorithms have been published (83-85).

Conflict of Interest: The author declares that he has no conflict of interest.

\section{References}

1. Parsons DW, Jones S, Zhang X, Lin JC, Leary RJ, Angenendt $\mathrm{P}$, et al. An integrated genomic analysis of human glioblastoma multiforme. Science. 2008;321(5897):180712.

2. Schindler G, Capper D, Meyer J, Janzarik W, Omran H, Herold-Mende C, et al. Analysis of BRAF V600E mutation in 1,320 nervous system tumors reveals high mutation frequencies in pleomorphic xanthoastrocytoma, ganglioglioma and extra-cerebellar pilocytic astrocytoma. Acta Neuropathol. 2011;121(3):397-405.
3. Khuong-Quang DA, Buczkowicz P, Rakopoulos P, Liu XY, Fontebasso AM, Bouffet E, et al. K27M mutation in histone H3.3 defines clinically and biologically distinct subgroups of pediatric diffuse intrinsic pontine gliomas. Acta Neuropathol. 2012;124(3):439-47.

4. Bechet D, Gielen GG, Korshunov A, Pfister SM, Rousso C, Faury D, et al. Specific detection of methionine 27 mutation in histone 3 variants $(\mathrm{H} 3 \mathrm{~K} 27 \mathrm{M})$ in fixed tissue from high-grade astrocytomas. Acta Neuropathol. 2014;128(5):733-41.

5. Stichel D, Ebrahimi A, Reuss D, Schrimpf D, Ono T, Shirahata M, et al. Distribution of EGFR amplification, combined chromosome 7 gain and chromosome 10 loss, and TERT promoter mutation in brain tumors and their potential for the reclassification of IDHwt astrocytoma to glioblastoma. Acta Neuropathol. 2018;136(5):793-803.

6. Andreiuolo F, Lisner T, Zlocha J, Kramm C, Koch A, Bison $\mathrm{B}$, et al. H3F3A-G34R mutant high grade neuroepithelial neoplasms with glial and dysplastic ganglion cell components. Acta neuropathologica communications. 2019;7(1):78.

7. Capper D, Jones DTW, Sill M, Hovestadt V, Schrimpf $\mathrm{D}$, Sturm D, et al. DNA methylation-based classification of central nervous system tumours. Nature. 2018;555(7697):469-74.

8. Capper D, Stichel D, Sahm F, Jones DTW, Schrimpf D, Sill $\mathrm{M}$, et al. Practical implementation of DNA methylation and copy-number-based CNS tumor diagnostics: the Heidelberg experience. Acta Neuropathol. 2018;136(2):181210 .

9. Jaunmuktane Z, Capper D, Jones DTW, Schrimpf D, Sill M, Dutt M, et al. Methylation array profiling of adult brain tumours: diagnostic outcomes in a large, single centre. Acta Neuropathol Commun. 2019;7(1):24.

10. Pickles JC, Fairchild AR, Stone TJ, Brownlee L, Merve A, Yasin SA, et al. DNA methylation-based profiling for paediatric CNS tumour diagnosis and treatment: a population-based study. Lancet Child Adolesc Health. 2020;4(2):121-30.

11. Schiffer D, Giordana MT, Mauro A, Migheli A. Glial fibrillary acidic protein (GFAP) in human cerebral tumors. An immunohistochemical study. Tumori. 1983;69(2):95104.

12. Dhillon AP, Rode J. Immunohistochemical studies of $S 100$ protein and other neural characteristics expressed by granular cell tumour. Diagn Histopathol. 1983;6(1):23-8.

13. Wiedenmann B, Franke WW, Kuhn C, Moll R, Gould VE. Synaptophysin: a marker protein for neuroendocrine cells and neoplasms. Proc Natl Acad Sci U S A. 1986;83(10):3500-4.

14. van Muijen GN, Ruiter DJ, Franke WW, Achtstätter T, Haasnoot WH, Ponec $\mathrm{M}$, et al. Cell type heterogeneity of cytokeratin expression in complex epithelia and carcinomas as demonstrated by monoclonal antibod- 
ies specific for cytokeratins nos. 4 and 13. Exp Cell Res. 1986;162(1):97-113.

15. Hans CP, Weisenburger DD, Greiner TC, Gascoyne RD, Delabie J, Ott G, et al. Confirmation of the molecular classification of diffuse large B-cell lymphoma by immunohistochemistry using a tissue microarray. Blood. 2004;103(1):275-82.

16. Garcia-Verdugo JM, Doetsch F, Wichterle H, Lim DA, Alvarez-Buylla A. Architecture and cell types of the adult subventricular zone: in search of the stem cells. J Neurobiol. 1998;36(2):234-48.

17. Capper D, Zentgraf H, Balss J, Hartmann C, von Deimling A. Monoclonal antibody specific for IDH1 R132H mutation. Acta Neuropathol. 2009;118(5):599-601.

18. Capper D, Berghoff AS, Magerle M, Ilhan A, Wohrer A, Hackl M, et al. Immunohistochemical testing of BRAF V600E status in 1,120 tumor tissue samples of patients with brain metastases. Acta Neuropathol. 2012;123(2):223-33.

19. Capper D, Berghoff AS, von Deimling A, Preusser M. Clinical neuropathology practice news 2-2012: BRAF V600E testing. Clin Neuropathol. 2012;31(2):64-6.

20. Versteege I, Sevenet N, Lange J, Rousseau-Merck MF, Ambros P, Handgretinger R, et al. Truncating mutations of hSNF5/INI1 in aggressive paediatric cancer. Nature. 1998;394(6689):203-6.

21. Margol AS, Judkins AR. Pathology and diagnosis of SMARCB1-deficient tumors. Cancer Genet. 2014;207(9): 358-64.

22. Yan H, Parsons DW, Jin G, McLendon R, Rasheed BA, Yuan W, et al. IDH1 and IDH2 mutations in gliomas. N Engl J Med. 2009;360(8):765-73.

23. Hartmann C, Meyer J, Balss J, Capper D, Mueller W, Christians A, et al. Type and frequency of IDH1 and IDH2 mutations are related to astrocytic and oligodendroglial differentiation and age: a study of 1,010 diffuse gliomas. Acta Neuropathol. 2009;118(4):469-74.

24. Reuss DE, Sahm F, Schrimpf D, Wiestler B, Capper D, Koelsche C, et al. ATRX and IDH1-R132H immunohistochemistry with subsequent copy number analysis and IDH sequencing as a basis for an "integrated" diagnostic approach for adult astrocytoma, oligodendroglioma and glioblastoma. Acta Neuropathol. 2015;129(1):133-46.

25. Sahm F, Reuss D, Koelsche C, Capper D, Schittenhelm J, Heim S, et al. Farewell to oligoastrocytoma: in situ molecular genetics favor classification as either oligodendroglioma or astrocytoma. Acta Neuropathol. 2014;128(4):551-9.

26. Sahm F, von Deimling A. Farewell to oligoastrocytoma: response to letters. Acta Neuropathol. 2014.

27. Louis DN, Wesseling P, Paulus W, Giannini C, Batchelor TT, Cairncross JG, et al. cIMPACT-NOW update 1: Not Otherwise Specified (NOS) and Not Elsewhere Classified (NEC). Acta Neuropathol. 2018;135(3):481-4.

28. Brat DJ, Aldape K, Colman H, Figrarella-Branger D, Fuller GN, Giannini C, et al. cIMPACT-NOW update 5: rec- ommended grading criteria and terminologies for IDHmutant astrocytomas. Acta Nauropathol. 2020:10.1007/ s00401-020-2127-9.

29. Shirahata M, Ono T, Stichel D, Schrimpf D, Reuss DE, Sahm F, et al. Novel, improved grading system(s) for IDH-mutant astrocytic gliomas. Acta Neuropathol. 2018;136(1):153-66.

30. von Deimling A, Ono T, Shirahata M, Louis DN. Grading of Diffuse Astrocytic Gliomas: A Review of Studies Before and After the Advent of IDH Testing. Seminars in neurology. 2018;38(1):19-23.

31. Ichimura K, Pearson DM, Kocialkowski S, Backlund LM, Chan R, Jones DT, et al. IDH1 mutations are present in the majority of common adult gliomas but rare in primary glioblastomas. Neuro Oncol. 2009;11(4):341-7.

32. Reuss DE, Kratz A, Sahm F, Capper D, Schrimpf D, Koelsche C, et al. Adult IDH wild type astrocytomas biologically and clinically resolve into other tumor entities. Acta Neuropathol. 2015;130(3):407-17.

33. Brat DJ, Aldape K, Colman H, Holland EC, Louis DN, Jenkins RB, et al. cIMPACT-NOW update 3: recommended diagnostic criteria for "Diffuse astrocytic glioma, IDHwildtype, with molecular features of glioblastoma, WHO grade IV”. Acta Neuropathol. 2018;136(5):805-10.

34. Schwartzentruber J, Korshunov A, Liu XY, Jones DT, Pfaff E, Jacob K, et al. Driver mutations in histone H3.3 and chromatin remodelling genes in paediatric glioblastoma. Nature. 2012;482(7384):226-31.

35. Mohammad F, Weissmann S, Leblanc B, Pandey DP, Hojfeldt JW, Comet I, et al. EZH2 is a potential therapeutic target for H3K27M-mutant pediatric gliomas. Nat Med. 2017;23(4):483-92.

36. Filbin MG, Tirosh I, Hovestadt V, Shaw ML, Escalante LE, Mathewson ND, et al. Developmental and oncogenic programs in H3K27M gliomas dissected by single-cell RNAseq. Science. 2018;360(6386):331-5.

37. Schreck KC, Ranjan S, Skorupan N, Bettegowda C, Eberhart CG, Ames HM, et al. Incidence and clinicopathologic features of $\mathrm{H} 3 \mathrm{~K} 27 \mathrm{M}$ mutations in adults with radiographically-determined midline gliomas. J Neuro-Oncol. 2019;143(1):87-93.

38. Louis DN, Giannini C, Capper D, Paulus W, Figarella-Branger $\mathrm{D}$, Lopes $\mathrm{MB}$, et al. cIMPACT-NOW update 2: diagnostic clarifications for diffuse midline glioma, H3 K27M-mutant and diffuse astrocytoma/ anaplastic astrocytoma, IDH-mutant. Acta Neuropathol. 2018;135(4):639-42.

39. Gessi M, Capper D, Sahm F, Huang K, von Deimling A, Tippelt S, et al. Evidence of H3 K27M mutations in posterior fossa ependymomas. Acta Neuropathol. 2016;132(4):635-7.

40. Morita S, Nitta M, Muragaki Y, Komori T, Masui K, Maruyama $\mathrm{T}$, et al. Brainstem pilocytic astrocytoma with H3 K27M mutation: case report. J Neurosurg. 2018;129(3):593-7. 
41. Pages M, Beccaria K, Boddaert N, Saffroy R, Besnard A, Castel D, et al. Co-occurrence of histone H3 K27M and BRAF V600E mutations in paediatric midline grade I ganglioglioma. Brain Pathol. 2018;28(1):103-11.

42. Korshunov A, Ryzhova M, Hovestadt V, Bender S, Sturm D, Capper D, et al. Integrated analysis of pediatric glioblastoma reveals a subset of biologically favorable tumors with associated molecular prognostic markers. Acta Neuropathol. 2015;129(5):669-78.

43. Korshunov A, Capper D, Reuss D, Schrimpf D, Ryzhova M, Hovestadt V, et al. Histologically distinct neuroepithelial tumors with histone 3 G34 mutation are molecularly similar and comprise a single nosologic entity. Acta Neuropathol. 2016;131(1):137-46.

44. Pekmezci M, Villanueva-Meyer JE, Goode B, Van Ziffle J, Onodera C, Grenert JP, et al. The genetic landscape of ganglioglioma. Acta Neuropathol Commun. 2018;6(1):47.

45. Koelsche C, Wohrer A, Jeibmann A, Schittenhelm J, Schindler G, Preusser M, et al. Mutant BRAF V600E protein in ganglioglioma is predominantly expressed by neuronal tumor cells. Acta Neuropathol. 2013;125(6):891-900.

46. Blumcke I, Coras R, Wefers AK, Capper D, Aronica E, Becker A, et al. Review: Challenges in the histopathological classification of ganglioglioma and DNT: microscopic agreement studies and a preliminary genotype-phenotype analysis. Neuropathol Appl Neurobiol. 2019;45(2):95-107.

47. Phillips JJ, Gong H, Chen K, Joseph NM, van Ziffle J, Bastian BC, et al. The genetic landscape of anaplastic pleomorphic xanthoastrocytoma. Brain Pathol. 2019;29(1):85-96.

48. Lee EQ, Ruland S, LeBoeuf NR, Wen PY, Santagata S. Successful Treatment of a Progressive BRAF V600E-Mutated Anaplastic Pleomorphic Xanthoastrocytoma With Vemurafenib Monotherapy. J Clin Oncol. 2016;34(10):e87-9.

49. 49. Brown NF, Carter T, Mulholland P. Dabrafenib in BRAFV600-mutated anaplastic pleomorphic xanthoastrocytoma. CNS oncology. 2017;6(1):5-9.

50. Jones DT, Kocialkowski S, Liu L, Pearson DM, Backlund LM, Ichimura K, et al. Tandem duplication producing a novel oncogenic BRAF fusion gene defines the majority of pilocytic astrocytomas. Cancer Res. 2008;68(21):8673-7.

51. Lin A, Rodriguez FJ, Karajannis MA, Williams SC, Legault $\mathrm{G}$, Zagzag $\mathrm{D}$, et al. BRAF alterations in primary glial and glioneuronal neoplasms of the central nervous system with identification of 2 novel KIAA1549:BRAF fusion variants. J Neuropathol Exp Neurol. 2012;71(1):66-72.

52. Jones DT, Hutter B, Jager N, Korshunov A, Kool M, Warnatz HJ, et al. Recurrent somatic alterations of FGFR1 and NTRK2 in pilocytic astrocytoma. Nat Genet. 2013;45(8):927-32.

53. Collins VP, Jones DT, Giannini C. Pilocytic astrocytoma: pathology, molecular mechanisms and markers. Acta Neuropathol. 2015;129(6):775-88.

54. Reinhardt A, Stichel D, Schrimpf D, Sahm F, Korshunov A, Reuss DE, et al. Anaplastic astrocytoma with piloid features, a novel molecular class of IDH wildtype glioma with recurrent MAPK pathway, CDKN2A/B and ATRX alterations. Acta Neuropathol. 2018;136(2):273-91.

55. Appay R, Pages M, Colin C, Jones DTW, Varlet P, Figarella-Branger D. Diffuse leptomeningeal glioneuronal tumor: a double misnomer? A report of two cases. Acta Neuropathol Commun. 2020;8(1):95.

56. 5Gardiman MP, Fassan M, Orvieto E, D’Avella D, Denaro L, Calderone M, et al. Diffuse leptomeningeal glioneuronal tumors: a new entity? Brain Pathol. 2010;20(2):361-6.

57. Deng MY, Sill M, Chiang J, Schittenhelm J, Ebinger M, Schuhmann MU, et al. Molecularly defined diffuse leptomeningeal glioneuronal tumor (DLGNT) comprises two subgroups with distinct clinical and genetic features. Acta Neuropathol. 2018;136(2):239-53.

58. Rivera B, Gayden T, Carrot-Zhang J, Nadaf J, Boshari T, Faury D, et al. Germline and somatic FGFR1 abnormalities in dysembryoplastic neuroepithelial tumors. Acta Neuropathol. 2016;131(6):847-63.

59. Singh D, Chan JM, Zoppoli P, Niola F, Sullivan R, Castano A, et al. Transforming fusions of FGFR and TACC genes in human glioblastoma. Science. 2012;337(6099):1231-5.

60. Gessi M, Moneim YA, Hammes J, Goschzik T, Scholz M, Denkhaus D, et al. FGFR1 mutations in Rosette-forming glioneuronal tumors of the fourth ventricle. J Neuropathol Exp Neurol. 2014;73(6):580-4.

61. Ellison DW, Hawkins C, Jones DTW, Onar-Thomas A, Pfister SM, Reifenberger G, et al. cIMPACT-NOW update 4: diffuse gliomas characterized by MYB, MYBL1, or FGFR1 alterations or BRAF(V600E) mutation. Acta Neuropathol. 2019;137(4):683-7.

62. Thom M, Toma A, An S, Martinian L, Hadjivassiliou G, Ratilal B, et al. One hundred and one dysembryoplastic neuroepithelial tumors: an adult epilepsy series with immunohistochemical, molecular genetic, and clinical correlations and a review of the literature. J Neuropathol Exp Neurol. 2011;70(10):859-78.

63. Chappe C, Padovani L, Scavarda D, Forest F, Nanni-Metellus I, Loundou A, et al. Dysembryoplastic neuroepithelial tumors share with pleomorphic xanthoastrocytomas and gangliogliomas BRAF(V600E) mutation and expression. Brain Pathol. 2013;23(5):574-83.

64. Lee D, Cho YH, Kang SY, Yoon N, Sung CO, Suh YL. BRAF V600E mutations are frequent in dysembryoplastic neuroepithelial tumors and subependymal giant cell astrocytomas. J Surg Oncol. 2014.

65. Qaddoumi I, Orisme W, Wen J, Santiago T, Gupta K, Dalton JD, et al. Genetic alterations in uncommon low-grade neuroepithelial tumors: BRAF, FGFR1, and MYB mutations occur at high frequency and align with morphology. Acta Neuropathol. 2016;131(6):833-45.

66. Wefers AK, Stichel D, Schrimpf D, Coras R, Pages M, Tauziède-Espariat $\mathrm{A}$, et al. Isomorphic diffuse glioma is a morphologically and molecularly distinct tumour entity with 
recurrent gene fusions of MYBL1 or MYB and a benign disease course. Acta Neuropathol. 2020;139(1):193-209.

67. Pajtler KW, Witt H, Sill M, Jones DT, Hovestadt V, Kratochwil F, et al. Molecular Classification of Ependymal Tumors across All CNS Compartments, Histopathological Grades, and Age Groups. Cancer Cell. 2015;27(5):728-43.

68. Ghasemi DR, Sill M, Okonechnikov K, Korshunov A, Yip S, Schutz PW, et al. MYCN amplification drives an aggressive form of spinal ependymoma. Acta Neuropathol. 2019.

69. Marinoff AE, Ma C, Guo D, Snuderl M, Wright KD, Manley PE, et al. Rethinking childhood ependymoma: a retrospective, multi-center analysis reveals poor long-term overall survival. J Neurooncol. 2017.

70. Pajtler KW, Mack SC, Ramaswamy V, Smith CA, Witt $\mathrm{H}$, Smith A, et al. The current consensus on the clinical management of intracranial ependymoma and its distinct molecular variants. Acta Neuropathol. 2017;133(1):5-12.

71. Ruda R, Reifenberger G, Frappaz D, Pfister SM, Laprie A, Santarius T, et al. EANO guidelines for the diagnosis and treatment of ependymal tumors. Neuro Oncol. 2018;20(4):445-56.

72. Mack SC, Taylor MD. Put away your microscopes: the ependymoma molecular era has begun. Curr Opin Oncol. 2017.

73. Fukuoka K, Kanemura Y, Shofuda T, Fukushima S, Yamashita S, Narushima D, et al. Significance of molecular classification of ependymomas: C11orf95-RELA fusionnegative supratentorial ependymomas are a heterogeneous group of tumors. Acta Neuropathol Commun. 2018;6(1):134.

74. Parker M, Mohankumar KM, Punchihewa C, Weinlich R, Dalton JD, Li Y, et al. C11orf95-RELA fusions drive oncogenic NF-kappaB signalling in ependymoma. Nature. 2014;506(7489):451-5.

75. Gessi M, Giagnacovo M, Modena P, Elefante G, Gianno F, Buttarelli FR, et al. Role of Immunohistochemistry in the Identification of Supratentorial C11ORF95-RELA Fused Ependymoma in Routine Neuropathology. Am J Surg Pathol. 2019;43(1):56-63.

76. Witt H, Mack SC, Ryzhova M, Bender S, Sill M, Isserlin $\mathrm{R}$, et al. Delineation of two clinically and molecularly distinct subgroups of posterior fossa ependymoma. Cancer Cell. 2011;20(2):143-57.
77. Wani K, Armstrong TS, Vera-Bolanos E, Raghunathan A, Ellison D, Gilbertson R, et al. A prognostic gene expression signature in infratentorial ependymoma. Acta Neuropathol. 2012;123(5):727-38.

78. Panwalkar P, Clark J, Ramaswamy V, Hawes D, Yang F, Dunham C, et al. Immunohistochemical analysis of H3K$27 \mathrm{me} 3$ demonstrates global reduction in group-A childhood posterior fossa ependymoma and is a powerful predictor of outcome. Acta Neuropathol. 2017.

79. Lee JC, Sharifai N, Dahiya S, Kleinschmidt-DeMasters BK, Rosenblum MK, Reis GF, et al. Clinicopathologic features of anaplastic myxopapillary ependymomas. Brain Pathol. 2019;29(1):75-84.

80. Mack SC, Pajtler KW, Chavez L, Okonechnikov K, Bertrand KC, Wang X, et al. Therapeutic targeting of ependymoma as informed by oncogenic enhancer profiling. Nature. 2018;553(7686):101-5.

81. Brandner S, Hilton DA, Jaunmuktane Z, Thom M, Ansorge $\mathrm{O}$, Roncaroli $\mathrm{F}$, et al. Dataset for tumours of the central nervous system, including the pituitary gland (5th edition). The Royal College of Pathologists. 2019.

82. Pickles JC, Stone TJ, Jacques TS. Methylation-based algorithms for diagnosis: experience from neuro-oncology. J Pathol. 2020;250(5):510-7.

83. Nassiri F, Mamatjan Y, Suppiah S, Badhiwala JH, Mansouri S, Karimi S, et al. DNA methylation profiling to predict recurrence risk in meningioma: development and validation of a nomogram to optimize clinical management. Neuro Oncol. 2019;21(7):901-10.

84. Paramasivam N, Hübschmann D, Toprak UH, Ishaque N, Neidert M, Schrimpf D, et al. Mutational patterns and regulatory networks in epigenetic subgroups of meningioma. Acta Neuropathol. 2019;138(2):295-308.

85. Suppiah S, Nassiri F, Bi WL, Dunn IF, Hanemann CO, Horbinski CM, et al. Molecular and translational advances in meningiomas. Neuro Oncol. 2019;21(Suppl 1):i4-i17.

86. Brandner S, Jaunmuktane Z. IDH mutant astrocytoma: biomarkers for prognostic stratification and the next frontiers. Neuropathol Appl Neurobiol. 2018.

87. Archer TC, Pomeroy SL. Defining the molecular landscape of ependymomas. Cancer Cell. 2015;27(5):613-5. 